\title{
Italian Magnetic Network and magnetic reference fields at 2010.0
}

\author{
Guido Dominici, Antonio Meloni, Angelo Di Ponzio, Massimo Miconi
}

Istituto Nazionale di Geofisica e Vulcanologia, Roma, Italy

\author{
Article history \\ Received October 6, 2011; accepted May 23, 2012. \\ Subject classification: \\ Earth's magnetic field, Geomagnetic map, Magnetic surveys, Magnetic repeat stations, Secular variation, Global and regional models.
}

\begin{abstract}
The Istituto Nazionale di Geofisica e Vulcanologia (INGV) has systematically undertaken the task of making measurements of the Earth's magnetic field in Italy. By tradition and because of the elongated geometric shape of our peninsula and islands, in Italy, a grid of more than 110 points, called the first order repeat stations, with an average spacing around 55-60 km, is in operation. Over this grid the measurements are repeated regularly, every 5 years. A survey of 131 repeat stations of the Italian Magnetic Network (including 2 observatories, 11 stations in Albania, 3 stations in Corsica and 1 in Malta) was carried out between 2009 and 2010 with the main purpose of updating our magnetic cartography. We describe the characteristics of magnetic first and second order networks, the magnetic measurements and the data reduction procedure. In agreement with the recommendations of MagNetE Committee, we report new repeat station data measured and reduced at 2010.0. An analytical expression, a second order polynomial, in latitude and longitude for the field elements, was determined, and coefficients for 2010.0 and average secular variation over the period 2005-2010, were obtained. The new maps for Italy, for D, F, H and $Z$ at the epoch 2010.0, are shown. A selection of stations from the Italian Magnetic Network, based on their low values of anomaly with respect to a 'normal' field, is also proposed for future surveys.
\end{abstract}

\section{Introduction}

Geomagnetism is a key property of our planet. A background in geomagnetism can be found, for example, in Merrill et al. [1996], Campbell [2003], Lanza and Meloni [2006]. The existence of a geomagnetic field allows animals, and human beings using a compass, to use it for orientation information. In this regard, the observation of the angular difference with respect to the geographic meridian North direction, the so called declination, has provided, for centuries, direction for navigation purposes.

In Italy, a long history of Earth's magnetic measurements and practice can be dated back in time at least to the 17 th century but the stable engagement in regularly repeated magnetic measurements, started only after the national unification at the end of the $19^{\text {th }}$ century. In the 20th century, since the 1930's, a modern Italian Magnetic Network composed of repeat stations, regularly distributed over the Italian territory, and integrated by magnetic observatories, has allowed the systematic determination of the spatial structure and the time variation characteristics of the Earth's magnetic field over the country [Cafarella et al. 1992a, 1992b].

Table 1 shows a brief history of all magnetic surveys made in the Italian territory starting from 1640 to present, indicating the observed magnetic elements, together with the number of repeat stations (\# Sites) and the corresponding observers (or Institutions involved). The magnetic survey of 1891-92 represents the first 3-component magnetic survey in the then unified kingdom of Italy. The latest modern magnetic surveys are reported in Molina et al. [1985], Meloni et al. [1988, 1994], Coticchia et al. [2001] and Dominici et al. [2007]. The latest modern magnetic surveys made at the European level are reported in Korte and Fredow [2001] and Mandea [2004], for example.

\section{The Italian Magnetic Network}

Because of its institutional role, and with consideration to the peculiar geometric shape of our peninsula and islands, the Istituto Nazionale di Geofisica e Vulcanologia (INGV) undertakes a survey of measurements on the "first order network" every five years. In the latest survey of 2010, measurements were made at 131 repeat stations including 2 observatories, 11 stations in Albania, 3 stations in Corsica and 1 in Malta, as shown in Figure 1. An agreement with Albania allows to make common measurements on a network there established in previous surveys [Chiappini et al. 1997]. The principal aims of this latest survey are the new magnetic maps compilation, the observation of secular variation of geomagnetic field elements and the computation of regional models to represent the main geomagnetic field elements pattern over Italy.

Magnetic repeat stations must satisfy the following requirements: i) absence of significant artificial and natural disturbance (for 'natural' we mean to avoid volcanic or other evident natural local anomaly source); ii) be representative of a quite large area (since we have avoided possible disturbances); iii) availability of bearings for azimuths with respect to the local 


\begin{tabular}{|c|c|c|c|}
\hline Epoch & Mag. elements & \#Sites & Observer \\
\hline 1640 & $\mathrm{D}$ & 21 & Fathers? Borri-Martini \\
\hline 1805-07 & $\mathrm{I}, \mathrm{H}$ & 15 & Humboldt \\
\hline $1845-56$ & $\mathrm{D}, \mathrm{I}, \mathrm{H}$ & 24 & Kreil - Fritsch \\
\hline $1875-78$ & $\mathrm{D}, \mathrm{I}, \mathrm{H}$ & 77 & Father Denza \\
\hline 1881-92 & $\mathrm{D}, \mathrm{I}, \mathrm{H}$ & 284 & UCMG(Chistoni-Palazzo) \\
\hline $1932-38$ & $\mathrm{D}, \mathrm{I}, \mathrm{H}$ & $46(1496)$ & IGMI \\
\hline 1948 & $\mathrm{D}, \mathrm{I}, \mathrm{H}$ & 46 & IGMI \\
\hline 1959 & $\mathrm{D}, \mathrm{I}, \mathrm{H}$ & 46 & IGMI \\
\hline 1965 & $\mathrm{D}, \mathrm{I}, \mathrm{H}$ & 28 & ING+Universities \\
\hline 1973 & $\mathrm{D}, \mathrm{I}, \mathrm{H}$ & 50 & IGMI \\
\hline 1979 & D,I,F & $106(2252)$ & ING+ Universities \\
\hline 1985 & D,I,F & 106 & ING+IGMI \\
\hline 1987.5 & $\mathrm{D}, \mathrm{I}, \mathrm{F}$ & 46 & ING \\
\hline 1990 & $\mathrm{D}, \mathrm{I}, \mathrm{F}$ & 116 & ING \\
\hline 1995 & $\mathrm{D}, \mathrm{I}, \mathrm{F}$ & $46+10$ Albania & ING \\
\hline 2000 & D,I,F & 114 & INGV (Charts with IGMI) \\
\hline 2005 & $\mathrm{D}, \mathrm{I}, \mathrm{F}$ & $117+3$ Corsica +11 Albania & INGV (Charts with IGMI) \\
\hline 2007.5 & $\mathrm{D}, \mathrm{I}, \mathrm{F}$ & 36 & INGV \\
\hline 2010.0 & D,I,F & $114+3$ Corsica +11 Albania +1 Malta & INGV \\
\hline
\end{tabular}

Table 1. History of magnetic surveys in Italy from 1640 to present. Acronyms are explained within the text. Additional acronym of UCMG stands for the Italian Central Office of Meteorology. Brackets (...) indicate second order network measurements, i.e. only F, H, Z.

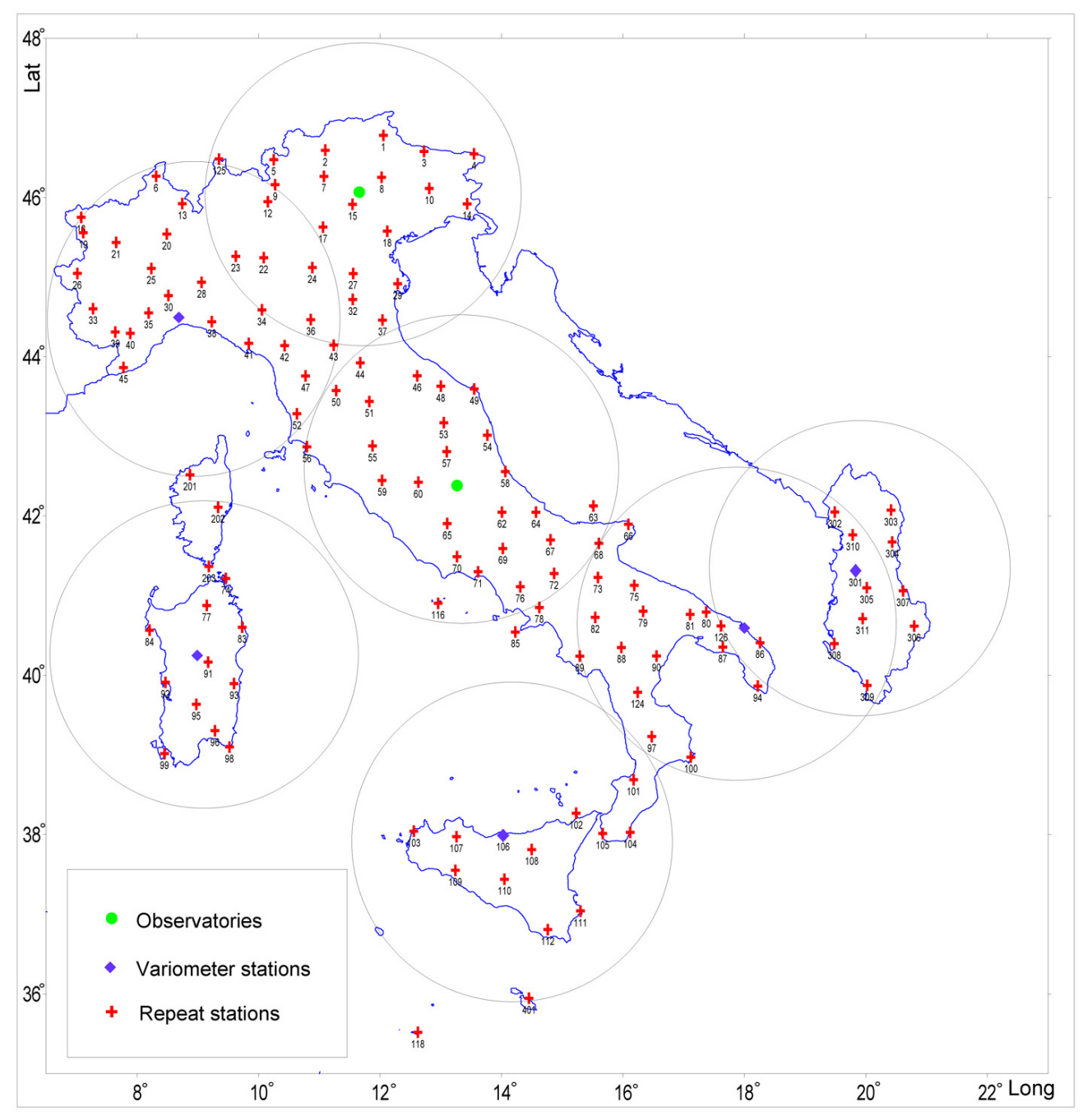

Figure 1. Italian repeat station network. Red crosses indicate repeat stations, filled circles indicate observatories and diamonds indicate variometer stations; large circles indicate coverage areas for rapid time variations as recorded at observatories and variometer stations. 
geographic meridian. A magnetic repeat station consists of a mark on a concrete pillar, or on platform of a $1 \mathrm{~m}^{2}$ in the area of the location selected for the magnetic measurement. In Jankowsky and Suckdorff [1996] a full general description of magnetic repeat station characteristics is reported.

For each repeat station, a monograph (an example is shown in Figure 2) is prepared for the purpose of keeping note of magnetic measurements there taken, and to allow a quick determination of the correct location.

To meet all necessary requirements, the monograph consists of two parts: first, we have indications about the local area (e.g., the land owner), a brief description about

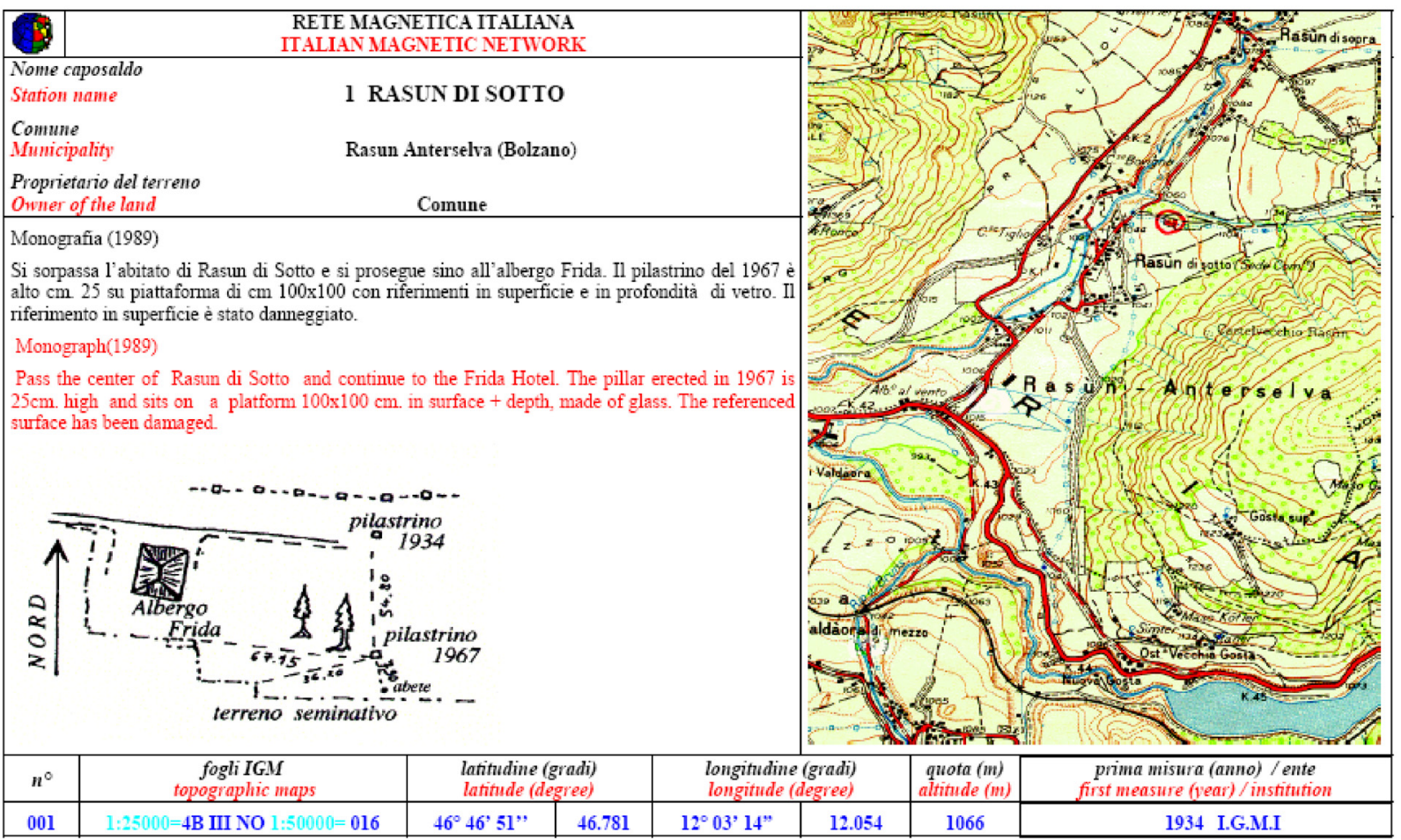

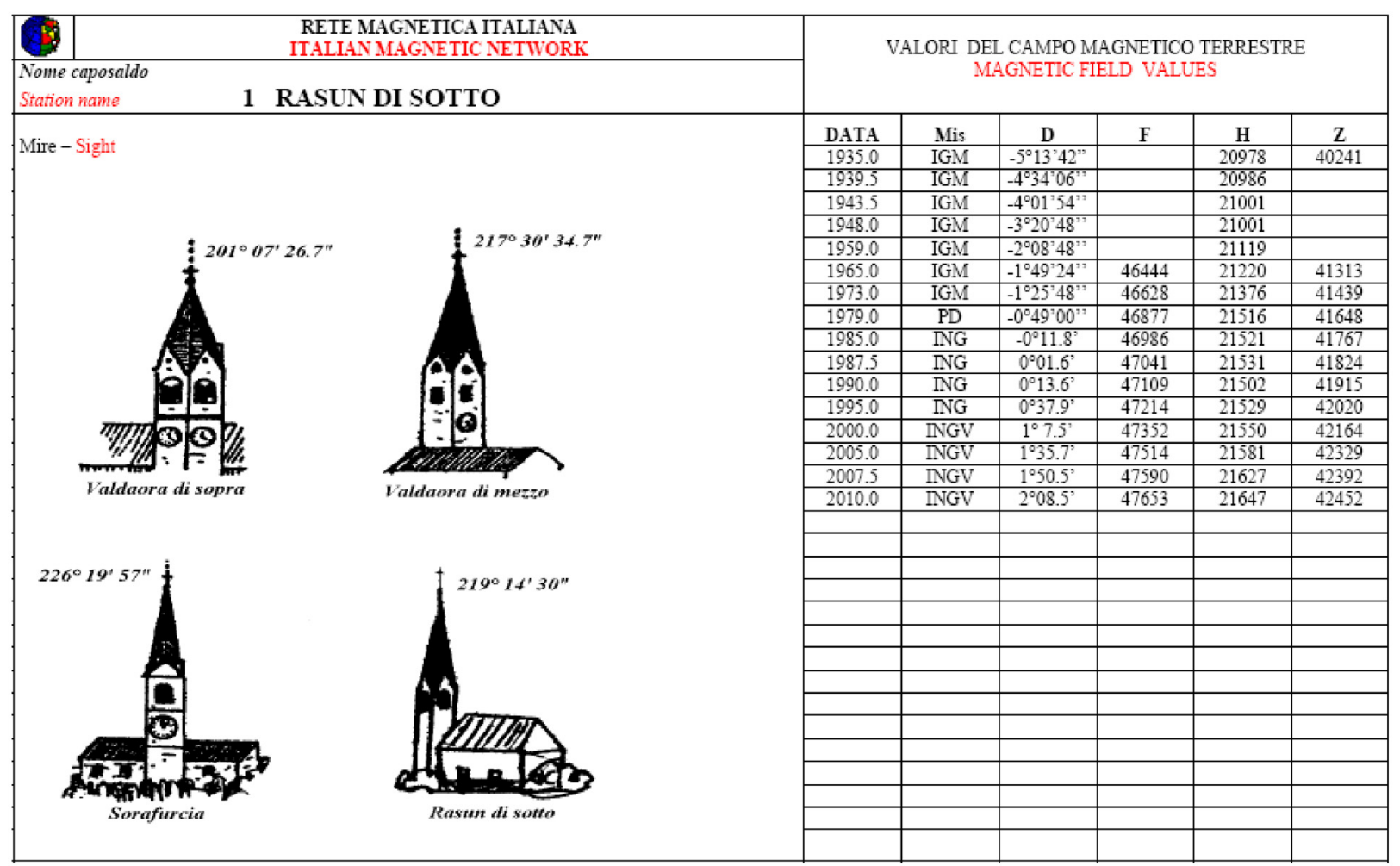

Figure 2. Example of a repeat station monograph, prepared for the purpose of keeping note of the magnetic measurements, and to allow a quick determination of the correct location. 
how to reach the location with the help of a detailed map, coordinates and altitude of the site, together with the date of the first series of measurements. In addition, the Italian institution that first occupied the repeat station is indicated by one of the following acronyms:

IGMI Istituto Geografico Militare Italiano, Florence; INGV (ING, before 2000) Istituto Nazionale di Geofisica e Vulcanologia, Rome;

PADOVA Istituto di Fisica Terrestre, University of Padua; FERRARA Istituto di Mineralogia, University of Ferrara; GENOVA Istituto Geofisico e Geodetico, University of Genoa;

NAPOLI Osservatorio Vesuviano, Naples;

BARI Istituto di Geodesia e Geofisica, University of Bari.

For a detailed description of the magnetic characteristics over a certain geographical area, a suitable spatial scale is desirable. However, in order to achieve this goal, the resolution of the first order network is not adequate. For this reason, a second order magnetic data network, with a higher spatial density of measurements, was deployed. In Italy, the second order network consists of 1529 points of declination (D) measurements, determined in the 1930s by the Military Geographical Institute (IGMI); information on this network can be found in Talamo [1975] in which the last survey accomplished by the IGMI is reported. For the horizontal intensity $(\mathrm{H})$, vertical intensity $(\mathrm{Z})$ and total field $(\mathrm{F})$, measurements undertaken in the period 1977-1981 on 2552 stations by the Finalized Project Geodinamica (PFG-CNR) are used. Information about this survey can be found in Molina et al. [1985].

In order to renew magnetic information on the second order network, data are updated on the basis of the resulting regional models obtained starting from the first order network new results. For the latest surveys $(2000,2005) I N G V$, in cooperation with IGMI, prepared a booklet containing the national maps of the magnetic elements at the specific epoch (for the various procedures utilized in map editing see, for example, Dominici et al. [2007]).

\section{Magnetic measurements}

In the latest 2010 survey, traditional magnetic measuring systems for field measurements were used. A portable theodolite fitted with a fluxgate magnetometer, the so called Declination Inclination Magnetometer (DIM), was used for the angular measurements of the Earth's magnetic field, and a proton precession magnetometer was used for the measurement of the field intensity F. All other elements can be derived starting from these measurements. The same instruments are used for the measurements taken at observatories and have, therefore, high intrinsic accuracy. In case of field measurement operations, however, the accuracy of the final values has a larger error than what usually obtained in an observatory environment. Sources of error can occur as a consequence of temperature variations over the period of measurement, or because, in the field, the theodolite is positioned on a tripod, rather than on a more solid pillar (as in an observatory). Newitt et al. [1996] have suggested that, for the mid-geomagnetic latitudes, the typical errors for the elements observed on magnetic networks are: 20 " for D, $1.5 \mathrm{nT}$ for $\mathrm{H}, 1.0 \mathrm{nT}$ for $\mathrm{Z}, 0.5 \mathrm{nT}$ for $\mathrm{F}$. We assume these errors also for the results of this 2010.0 Italian survey.

For the azimuth determination, in the newly occupied stations, and in all cases in which the visibility of the old azimuth marks was limited or lacking, a gyroscopic theodolite was used. This instrument is preferred to Global Positioning System (GPS) instruments, since it can be used for measurements in tunnel or under roof-covered locations, or even where the presence of tall vegetation can cause GPS data problems, because of limited satellite visibility. Moreover, the two instruments show comparable precisions of about ten minutes of arc-second, on average.

As a rule, measurements are performed in series of 10 , of which 5 in the morning, and then 5 in the afternoon. The measurements are then undertaken avoiding the time period of maximum magnetic field change due to diurnal variation. Moreover, in order to reduce the final error due to the magnetic field, diurnal variation 02 UT (Universal Time) was selected as the time to which all data were reduced.

\section{Data analysis}

After magnetic elements are observed at the repeat stations, the magnetic data need to be reduced to a magnetic quiet time condition. The following procedure was used. As above mentioned, magnetic elements observed at the repeat stations, are reduced firstly to $02_{U T}$ (i.e., to correct for the diurnal variation correction) assuming that variometer data can be used as a correction for rapid external field variations under the assumption that their spatial variations are negligible. The value of an element $E$ (i.e., D, I or F) at station $s$, is reduced at $02_{U T}$ of day of measure $d$, by means of the following:

$$
E_{s}\left(02_{U T}\right)_{d}=E_{v a r}\left(02_{U T}\right)_{d}+\left[E_{s}(t)_{d}-E_{v a r}(t)_{d}\right]
$$

where $E_{s}\left(02_{U T}\right)_{d}=$ value of $E$ at station $s$ reduced at time $02_{U T}$ of day of measure $d ; E_{v a r}\left(02_{U T}\right)_{d}=$ value of $E$ at variometer station $s$ at time $02_{U T}$ of day of measure $d ; E_{s}(t)_{d}=$ value of element $E$ observed at station $s$ at time $t$ at that day $d ; E_{v a r}(t)_{d}=$ value of element $E$ at variometer station at time $t$ at that day $d$.

The element $E$ computed at epoch 2010.0 (January $1^{\text {st }}$, 2010) is obtained following:

$$
E_{s}(2010.0)=E_{o b s}(2010.0)+\left[E_{s}\left(02_{U T}\right)_{d}-E_{o b s}\left(02_{U T}\right)_{d}\right]
$$

where $E_{s}(2010.0)=$ value of $E$ at station $s$ reduced at epoch 2010.0; $E_{\text {obs }}(2010.0)=$ average value of $E$ at observatory at 
epoch 2010.0; $E_{o b s}\left(02_{U T}\right)_{d}=$ value of $E$ at observatory at time $02_{U T}$ of day of measure $d$.

In order to evaluate the average main field contribution in a given area, magnetic measurements are processed for the determination of a so called normal field. This is an analytical expression in latitude and longitude that best interpolates, for the region of interest, the longest wavelength part of the measured magnetic field. Such a normal field doesn't reflect a well defined physical source, since it can contain long wave crustal origin contributions superimposed to the core origin field; it suffices, however, as an analytical level, from which, for example, the local magnetic anomalies can be derived.

\begin{tabular}{|c|c|c|c|c|c|c|}
\hline Year & $a_{0}$ & $a_{1}$ & $a_{2}$ & $a_{3}$ & $a_{4}$ & $a_{5}$ \\
\hline \multicolumn{7}{|c|}{ Geomagnetic element: D (' ) } \\
\hline 2010.0 & 124.42 & 0.02717 & 0.20077 & -0.00005 & -0.00007 & 0.00004 \\
\hline 2007.5 & 109.27 & 0.02506 & 0.20228 & -0.00006 & -0.00012 & -0.00001 \\
\hline 2005.0 & 96.66 & 0.02072 & 0.19958 & -0.00006 & -0.00007 & 0.00007 \\
\hline 2000.0 & 70.88 & 0.01096 & 0.21182 & -0.00004 & -0.00004 & 0.00015 \\
\hline 1995.0 & 43.76 & 0.00692 & 0.23530 & -0.00007 & -0.00010 & 0.00007 \\
\hline 1990.0 & 18.64 & 0.00225 & 0.24493 & -0.00006 & -0.00005 & 0.00008 \\
\hline 1987.5 & 9.61 & -0.00539 & 0.24929 & -0.00006 & -0.00006 & 0.00017 \\
\hline 1985.0 & -4.73 & -0.00087 & 0.26177 & -0.00008 & -0.00007 & 0.00009 \\
\hline 1979.0 & -44.70 & -0.00041 & 0.28870 & -0.00004 & -0.00007 & 0.00014 \\
\hline \multicolumn{7}{|c|}{ Geomagnetic element: F (nT) } \\
\hline 2010.0 & 46216.4 & 5.71653 & 1.23053 & -0.00198 & -0.00006 & -0.00050 \\
\hline 2007.5 & 46130.1 & 5.71722 & 1.22369 & -0.00178 & -0.00018 & -0.00080 \\
\hline 2005.0 & 46064.0 & 5.72290 & 1.22295 & -0.00186 & -0.00004 & -0.00048 \\
\hline 2000.0 & 45889.2 & 5.71538 & 1.23341 & -0.00170 & 0.00035 & -0.00018 \\
\hline 1995.0 & 45735.4 & 5.69641 & 1.20307 & -0.00132 & 0.00011 & -0.00096 \\
\hline 1990.0 & 45641.0 & 5.67705 & 1.32444 & -0.00145 & 0.00003 & -0.00037 \\
\hline 1987.5 & 45547.7 & 5.72967 & 1.23966 & -0.00126 & 0.00065 & -0.00053 \\
\hline 1985.0 & 45506.8 & 5.68863 & 1.22593 & -0.00158 & 0.00048 & -0.00014 \\
\hline 1979.0 & 45388.4 & 5.70878 & 1.11079 & -0.00153 & 0.00049 & -0.00068 \\
\hline \multicolumn{7}{|c|}{ Geomagnetic element: $\mathrm{H}(\mathrm{nT})$} \\
\hline 2010.0 & 24381.5 & -9.45241 & -0.19877 & -0.00002 & -0.00002 & -0.00030 \\
\hline 2007.5 & 24327.7 & -9.35207 & -0.11631 & -0.00002 & 0.00021 & 0.00008 \\
\hline 2005.0 & 24284.5 & -9.38620 & -0.08992 & 0.00008 & -0.00008 & 0.00002 \\
\hline 2000.0 & 24223.0 & -9.29587 & -0.06509 & 0.00015 & 0.00028 & 0.00023 \\
\hline 1995.0 & 24192.2 & -9.26491 & -0.02292 & 0.00017 & -0.00007 & -0.00025 \\
\hline 1990.0 & 24166.4 & -9.27826 & 0.01689 & 0.00004 & -0.00001 & -0.00008 \\
\hline 1987.5 & 24163.4 & -9.19894 & 0.03969 & 0.00037 & 0.00015 & -0.00004 \\
\hline 1985.0 & 24162.0 & -9.15564 & 0.05196 & -0.00010 & 0.00030 & 0.00025 \\
\hline 1979.0 & 24104.2 & -9.04300 & 0.10973 & 0.00036 & 0.00004 & -0.00042 \\
\hline \multicolumn{7}{|c|}{ Geomagnetic element: $Z$ (nT) } \\
\hline 2010.0 & 39257.2 & 12.64859 & 1.56759 & -0.00490 & -0.00004 & -0.00075 \\
\hline 2007.5 & 39189.2 & 12.69073 & 1.52167 & -0.00512 & -0.00004 & -0.00080 \\
\hline 2005.0 & 39131.3 & 12.64462 & 1.58315 & -0.00472 & -0.00010 & -0.00102 \\
\hline 2000.0 & 38970.1 & 12.58348 & 1.52926 & -0.00462 & 0.00019 & -0.00044 \\
\hline 1995.0 & 38821.8 & 12.57978 & 1.48166 & -0.00448 & -0.00001 & -0.00145 \\
\hline 1990.0 & 38716.8 & 12.54693 & 1.53025 & -0.00449 & 0.00004 & -0.00081 \\
\hline 1987.5 & 38608.3 & 12.57667 & 1.44880 & -0.00429 & 0.00062 & -0.00097 \\
\hline 1985.0 & 38564.9 & 12.51772 & 1.42692 & -0.00456 & 0.00024 & -0.00083 \\
\hline 1979.0 & 38451.7 & 12.46703 & 1.25918 & -0.00444 & 0.00060 & -0.00069 \\
\hline
\end{tabular}

Table 2. Coefficients of normal fields for epochs from 1979 to 2010 for all magnetic elements. Latitude $\phi$ and longitude $\lambda$ are referred to $42^{\circ} \mathrm{N}$ and $12^{\circ} \mathrm{E}$ respectively, with values expressed in minutes of arc. $\phi=\left(\right.$ Lat. $\left.-42^{\circ}\right)$ in minutes; $\lambda=\left(\right.$ Long. $\left.-12^{\circ}\right)$ in minutes. 


\begin{tabular}{|c|c|c|c|c|c|c|}
\hline Epoch & $a_{0}$ & $a_{1}$ & $a_{2}$ & $a_{3}$ & $a_{4}$ & $a_{5}$ \\
\hline \multicolumn{7}{|c|}{ Geomagnetic element: D (' ) } \\
\hline $1985 / 79$ & 37.9 & -0.003 & -0.023 & 0.0001 & 0.00002 & 0.00003 \\
\hline $1990 / 85$ & 24.8 & -0.016 & & & & \\
\hline $1995 / 90$ & 23.1 & 0.003 & -0.016 & & & 0.00001 \\
\hline $2000 / 90$ & 51.2 & 0.010 & -0.028 & 0.00001 & 0.00002 & \\
\hline $2005 / 00$ & 25.8 & 0.008 & -0.011 & & 0.00001 & 0.00002 \\
\hline $2010 / 05$ & 27.7 & 0.008 & -0.006 & 0.00001 & 0.00002 & -0.00001 \\
\hline \multicolumn{7}{|c|}{ Geomagnetic element: F (nT) } \\
\hline $1985 / 79$ & 123.8 & -0.002 & 0.044 & -0.00006 & 0.00003 & 0.00010 \\
\hline $1990 / 85$ & 136.1 & -0.012 & 0.014 & -0.00006 & -0.00013 & -0.00012 \\
\hline $1995 / 90$ & 100.5 & -0.003 & -0.006 & 0.00005 & 0.00007 & 0.00001 \\
\hline $2000 / 90$ & 241.8 & 0.044 & 0.009 & 0.00012 & -0.00001 & 0.00018 \\
\hline $2005 / 00$ & 168.3 & 0.001 & 0.012 & -0.00002 & -0.00012 & -0.00007 \\
\hline $2010 / 05$ & 148.9 & -0.003 & & -0.00011 & -0.00001 & -0.00003 \\
\hline \multicolumn{7}{|c|}{ Geomagnetic element: $\mathrm{H}(\mathrm{nT})$} \\
\hline $1985 / 79$ & 49.5 & -0.095 & -0.082 & 0.00001 & 0.00017 & 0.00035 \\
\hline $1990 / 85$ & 1.5 & -0.086 & -0.053 & 0.00002 & -0.00008 & -0.00003 \\
\hline $1995 / 90$ & 30.1 & -0.035 & -0.016 & 0.00006 & & 0.00027 \\
\hline $2000 / 90$ & 63.6 & -0.030 & -0.088 & 0.00001 & 0.00022 & 0.00013 \\
\hline $2005 / 00$ & 54.4 & -0.067 & -0.030 & -0.00007 & -0.00012 & 0.00002 \\
\hline $2010 / 05$ & 93.2 & -0.080 & -0.048 & 0.00003 & & -0.00016 \\
\hline \multicolumn{7}{|c|}{ Geomagnetic element: $Z$ (nT) } \\
\hline $1985 / 79$ & 115.3 & 0.056 & 0.105 & -0.00009 & -0.00011 & -0.00015 \\
\hline $1990 / 85$ & 153.5 & 0.020 & 0.060 & -0.00010 & 0.00005 & -0.00009 \\
\hline $1995 / 90$ & 99.0 & 0.028 & 0.007 & 0.00004 & 0.00012 & -0.00007 \\
\hline $2000 / 90$ & 248.9 & 0.044 & 0.062 & 0.00001 & -0.00013 & 0.00005 \\
\hline $2005 / 00$ & 163.7 & 0.029 & 0.022 & & -0.00007 & -0.00009 \\
\hline $2010 / 05$ & 114.5 & 0.061 & 0.039 & -0.00008 & 0.00001 & 0.00008 \\
\hline
\end{tabular}

Table 3. Coefficients of normal fields secular variation for epochs from 1979 to 2010 for all magnetic elements. Latitude $\phi$ and longitude $\lambda$ are referred to $42^{\circ} \mathrm{N}$ and $12^{\circ} \mathrm{E}$ respectively, with values expressed in minutes of arc. $\phi=\left(\right.$ Lat. $\left.-42^{\circ}\right)$ in minutes; $\lambda=\left(\right.$ Long. $\left.-12^{\circ}\right)$ in minutes.

For the Italian region, in latest years we have computed a few reference fields: the normal fields INGRF (ING Reference Field) and ITGRF (ITalian Geomagnetic Reference Field); for this see for example De Santis et al. [2003]. These reference fields are based on a second-degree polynomial expression of the form

$$
E(\phi, \lambda)=a_{0}+a_{1} \phi+a_{2} \lambda+a_{3} \phi^{2}+a_{4} \lambda^{2}+a_{5} \phi \lambda
$$

where $E$ is the generic geomagnetic element, $\lambda$ the longitude, the latitude (both expressed in degrees or minutes of arc), $a_{0}$ is the base level of the models for each element, $a_{n(n=1,5)}$ are the coefficients (in $\mathrm{nT} /$ degree or $\mathrm{nT} /$ minutes of arc) in longitude and latitude that determine the spatial gradient for each element.

In the INGRF model, the coefficients $a_{n(n=0,5)}$ are determined by a least-squares error minimization technique from the repeat stations data. In order to identify the effect of stations located in anomalous areas, the polynomial coefficients were first computed using all the available stations and then the standard uncertainty associated with each single station $\sigma= \pm \sqrt{[\nu v] /(n-6)} \quad$ (where $[\nu v]$ is the sum of square differences between observed and computed values, $n$ is the number of stations and 6 is the number of coefficients) was computed. The stations with residuals larger than $2 \sigma$ were eliminated, and computation was iterated until no residuals exceeded $2 \sigma$ remained [for details see Molina et al. 1985 and Dominici et al. 2007].

The International Association of Geomagnetism and Aeronomy (IAGA) regularly releases the so called International Geomagnetic Reference Field (IGRF): the latest version of this standard mathematical description of the Earth's main magnetic field is IGRF 11 [see IAGA Working Group V-MOD 2010]. The coefficients for this degree and order 13 main field model were finalized by a task force of IAGA in December 2009. The IGRF is the product of a collaborative effort between magnetic field modelers and the institutes involved in collecting and disseminating magnetic field data 

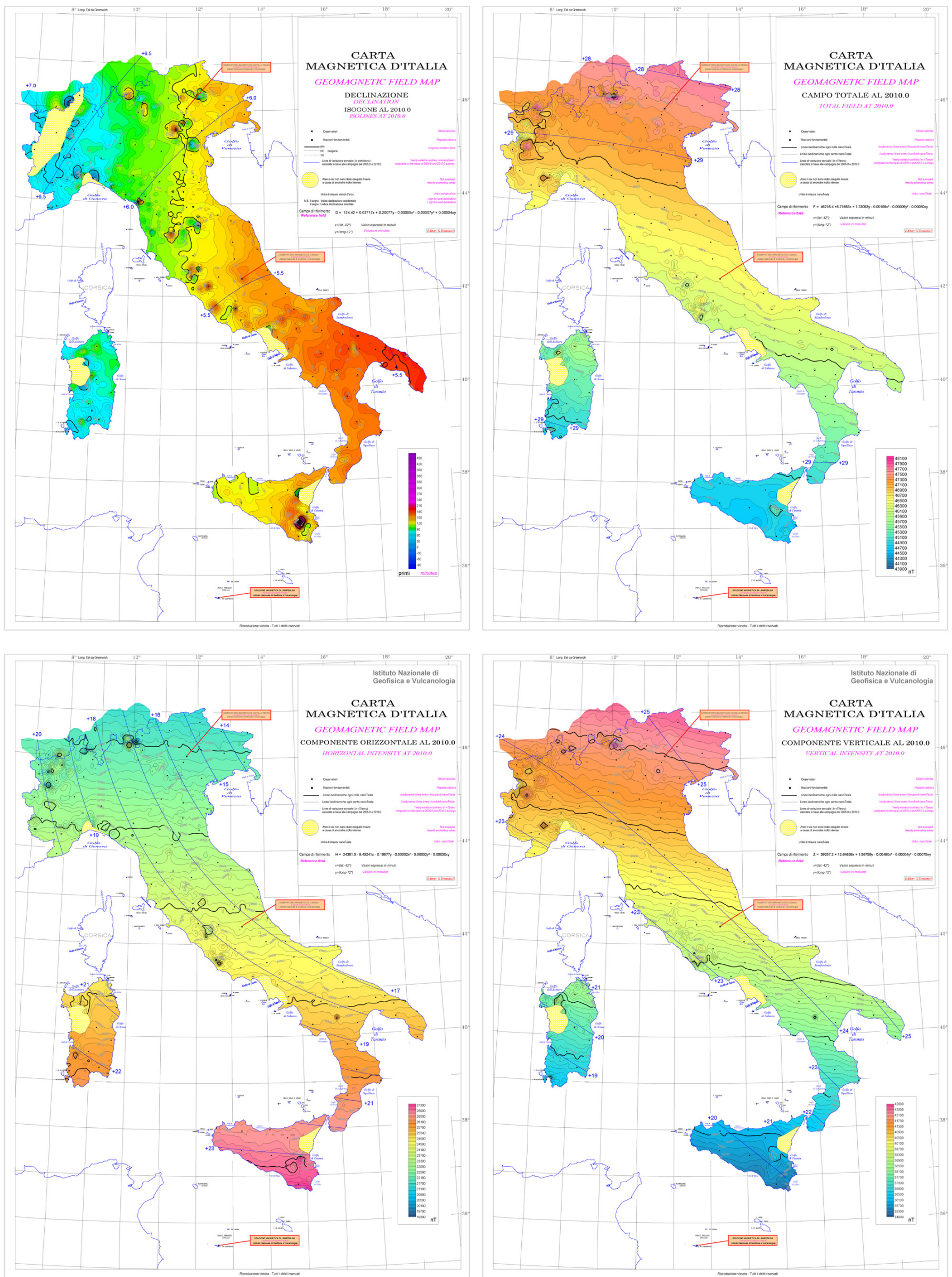

Figure 3. Top left: contour lines and coloured values of declination, D; top right: total intensity, F; bottom left: horizontal component, H; bottom right: vertical component, Z. All at 2010.0 over Italy. 

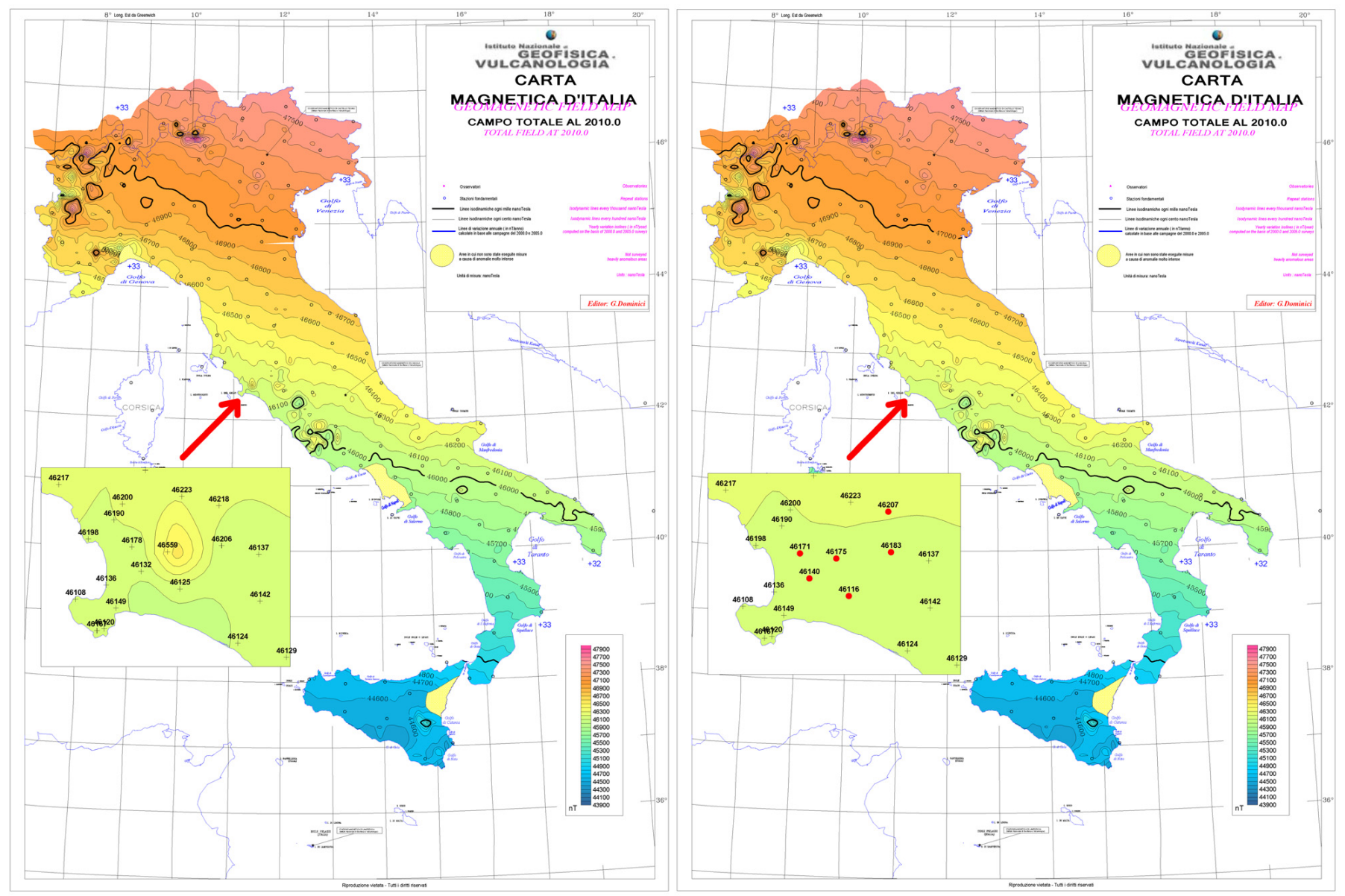

Figure 4. Left: map of total field F at 2010.0, before the revision in the Albegna basin. Right: map of F at 2010.0, corrected after re-measured data in local survey (red point in the enlargement).

from satellites and from observatories and surveys around the world. In the ITGRF model, the coefficients $a_{n(n=1,5)}$ are determined by a least squares technique for a grid, centered over Italy, of $12^{\circ} \times 11^{\circ}$, in which every point value is derived from the IGRF model and the value of $a_{0}$ comes from the annual mean value for each element at L'Aquila observatory. In this case, the derived model avoids the boundary effects that are present in the INGRF model; secular variation is determined by observatory measurements [for details see De Santis et al. 2003].

A second order polynomial in latitude and longitude has been used for computing secular variation for the period 2005-2010; by means of this model all the second order network points were adjusted and reduced to 2010.0. Tables 2 and 3 report the coefficient values of the normal fields and of the secular variation models for the all periods, respectively.

The second order network data were then updated using the latest 2010 survey with the intent of producing new magnetic element maps at 2010. The updated second order network database was interpolated using an "Inverse Distance Weighted" algorithm [see for example Shepard 1968], in order to produce a regular grid (step: 0.05 degree, about $5 \mathrm{~km}$ ) from which contour lines for magnetic elements were then drawn. In Figure 3 we show maps of the various field elements, reporting the general behaviour of geomagnetic field over Italy for the epoch 2010.0.

During the 2010 survey, a detailed investigation was performed in Tuscany (central Italy). In this region in fact, the visual inspection of the total field map had revealed a suspected magnetic anomaly, amplitude of about $400 \mathrm{nT}$, in the Monte Argentario area (Lat. $42.5^{\circ}$, Lon. $11.3^{\circ}$ ). In this area no natural probable geological source anomaly was found to support this feature. The anomaly was the result of a single data point value in the second order network. In order to verify this datum in the FHZ second order network database, new measurements on 19 stations around the anomalous area, were undertaken. The final result confirmed that the old datum was wrong and then the values in the database were recalculated and corrected. The result of this update is shown in detail in Figure 4.

\section{Future development and Conclusions}

Over the last thirty years, since the first complete survey of 1979.0 undertaken under the INGV coordination, the first order repeat station network has been updated every 5 years reoccupying all stations that was possible to repeat. In future, this practice may be subject to a revision for several reasons. One reason is the general reduction in funding to which all scientific institutions are subject, especially for financing future surveys. A second reason is the evaluation of 


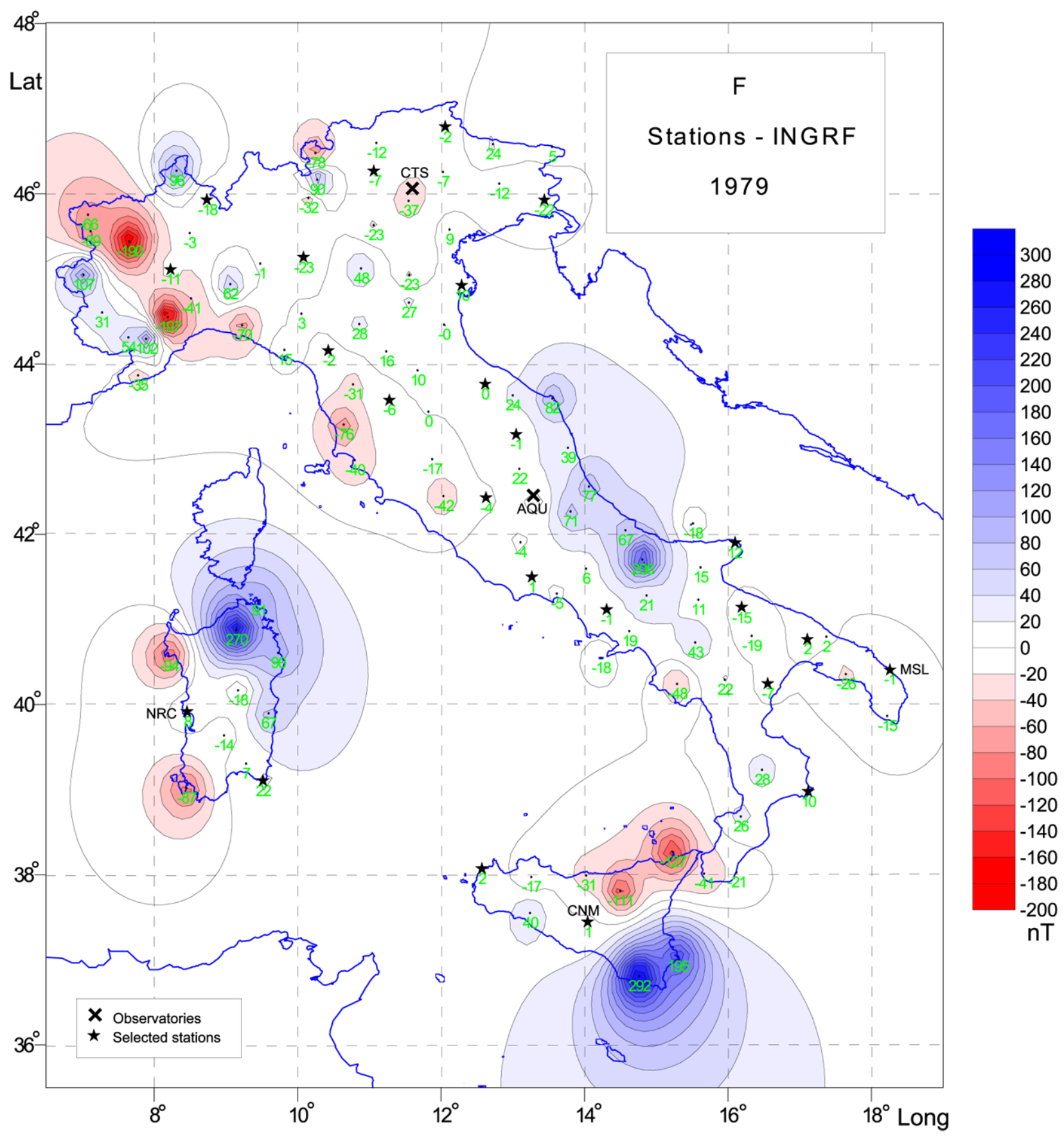

Figure 5. Anomalies of total field $\mathrm{F}$ at repeat stations with respect to INGRF at epoch 1979.0; units are nT; stars mark the location of repeat stations selected for a reduced network (see text).

the real scientific need to undertake the survey at such a large number of magnetic repeat stations. The difference between current repeat stations with respect to the INGRF79 (see Figure 5) shows that a more limited number of stations are already representative of the magnetic core field. Indeed 24 stations were found to be adequate to correctly represent the core field evolution. This selection of stations takes into account the geological characteristics, spatial distribution and low values of magnetic anomaly with respect to the core field (repeat stations with anomalies $< \pm 20 \mathrm{nT}$ in F). Using the selected 24 stations the average resulting spacing would increase considerably to around $100 \mathrm{~km}$. This situation was checked also for a possible new reduced regional field; we called this INGRF_reduced, that was computed for all epochs from 1985.0 to 2010.0 at intervals of 5 years. Table 4 reports the coefficient values of the normal fields for the different periods. In view of the above mentioned situation for next mid-term survey (2012.5) we will then make repeat station survey measurements only on the 24 selected stations, represented with stars in the map of Figure 5.

Since all models were developed using independent polynomials for each element, the self-consistency of the resulting field data values must be checked. This consistency may be checked by means of the geometrical condition, that is the difference between the total intensity $\mathrm{F}$ and the square root of the sum of squares of the horizontal and vertical 


\begin{tabular}{|c|c|c|c|c|c|c|}
\hline Year & $a_{0}$ & $a_{1}$ & $a_{2}$ & $a_{3}$ & $a_{4}$ & $a_{5}$ \\
\hline \multicolumn{7}{|c|}{ Geomagnetic element: D (' ) } \\
\hline 2010.0 & 126.83 & 0.02358 & 0.18933 & -0.00009 & -0.00003 & 0.00013 \\
\hline 2005.0 & 98.63 & 0.01617 & 0.20458 & -0.00010 & -0.00005 & 0.00018 \\
\hline 2000.0 & 72.43 & 0.00889 & 0.21451 & -0.00006 & -0.00006 & 0.00021 \\
\hline 1995.0 & 44.43 & 0.00086 & 0.22586 & -0.00007 & -0.00005 & 0.00017 \\
\hline 1990.0 & 23.64 & -0.00558 & 0.23765 & -0.00012 & -0.00010 & 0.00011 \\
\hline 1985.0 & -4.06 & -0.01256 & 0.26693 & -0.00005 & -0.00007 & 0.00023 \\
\hline \multicolumn{7}{|c|}{ Geomagnetic element: F (nT) } \\
\hline 2010.0 & 46208.2 & 5.71648 & 1.14375 & -0.00204 & 0.00048 & -0.00035 \\
\hline 2005.0 & 46063.0 & 5.71296 & 1.15238 & -0.00199 & 0.00032 & -0.00027 \\
\hline 2000.0 & 45891.8 & 5.68076 & 1.14367 & -0.00169 & 0.00042 & -0.00044 \\
\hline 1995.0 & 45751.2 & 5.63348 & 1.15905 & -0.00176 & 0.00034 & -0.00047 \\
\hline 1990.0 & 45645.5 & 5.66303 & 1.17613 & -0.00169 & 0.00051 & -0.00045 \\
\hline 1985.0 & 45513.0 & 5.67229 & 1.14444 & -0.00162 & 0.00052 & -0.00047 \\
\hline \multicolumn{7}{|c|}{ Geomagnetic element: $\mathrm{H}(\mathrm{nT})$} \\
\hline 2010.0 & 24384.0 & -9.42077 & -0.25341 & -0.00039 & 0.00063 & 0.00038 \\
\hline 2005.0 & 24292.8 & -9.37427 & -0.26215 & -0.00029 & 0.00064 & 0.00078 \\
\hline 2000.0 & 24237.9 & -9.31264 & -0.19031 & -0.00024 & 0.00052 & 0.00021 \\
\hline 1995.0 & 24201.4 & -9.29731 & -0.08127 & -0.00025 & 0.00049 & 0.00072 \\
\hline 1990.0 & 24172.6 & -9.25446 & -0.07385 & -0.00021 & 0.00044 & 0.00036 \\
\hline 1985.0 & 24167.1 & -9.15184 & -0.04246 & -0.00017 & 0.00058 & 0.00021 \\
\hline \multicolumn{7}{|c|}{ Geomagnetic element: $Z$ (nT) } \\
\hline 2010.0 & 39246.3 & 12.64554 & 1.51707 & -0.00481 & 0.00024 & -0.00092 \\
\hline 2005.0 & 39131.9 & 12.60684 & 1.53598 & -0.00479 & 0.00003 & -0.00108 \\
\hline 2000.0 & 38964.7 & 12.54371 & 1.47760 & -0.00446 & 0.00023 & -0.00090 \\
\hline 1995.0 & 38821.2 & 12.49570 & 1.43309 & -0.00453 & 0.00017 & -0.00118 \\
\hline 1990.0 & 38715.2 & 12.51470 & 1.44609 & -0.00448 & 0.00040 & -0.00095 \\
\hline 1985.0 & 38562.3 & 12.49154 & 1.38819 & -0.00441 & 0.00032 & -0.00087 \\
\hline \multicolumn{7}{|c|}{ Geomagnetic element: I (' ) } \\
\hline 2010.0 & 3488.44 & 1.09715 & 0.07674 & -0.00029 & -0.00002 & -0.00009 \\
\hline 2005.0 & 3489.76 & 1.09608 & 0.07821 & -0.00030 & -0.00003 & -0.00012 \\
\hline 2000.0 & 3486.65 & 1.09363 & 0.07162 & -0.00029 & -0.00002 & -0.00008 \\
\hline 1995.0 & 3483.25 & 1.09464 & 0.06338 & -0.00029 & -0.00002 & -0.00012 \\
\hline 1990.0 & 3480.90 & 1.09524 & 0.06359 & -0.00029 & -0.00001 & -0.00009 \\
\hline 1985.0 & 3475.13 & 1.09165 & 0.05947 & -0.00030 & -0.00002 & -0.00007 \\
\hline
\end{tabular}

Table 4. Coefficients of reduced normal field for epochs 1985 to 2010 for all magnetic elements. Latitude $\phi$ and longitude $\lambda$ are referred to $42^{\circ} \mathrm{N}$ and $12^{\circ} \mathrm{E}$ respectively, with values expressed in minutes of arc. $\phi=\left(\right.$ Lat. $\left.-42^{\circ}\right)$ in minutes, $\lambda=\left(\right.$ Long. $\left.-12^{\circ}\right)$ in minutes.

component $D F=F-\sqrt{H^{2}+Z^{2}}$. The closer this difference value is to a zero level, the better the consistency is. In Figure 6 we show the geometrical condition at the epoch 2000.0 for the models INGRF, ITGRF (this is the last update for this model) and the condition for INGRF_reduced at the epochs 2000.0 and 2010.0: from this comparison we can see that the differences over the Italian territory are small and on the overall consistent for the two epochs for the INGRF_reduced and also with a smaller gradient respect the ITGRF and INGRF.

In these sites we tested the validity of the regional models by the comparison of the values predicted by models with the annual means of the observatories or the measurements in the stations. In Figure 5 the crosses mark the location of the two observatories of Castello Tesino (CTS) and L'Aquila (AQU). The stars mark the repeat stations of Masseria Lamia (MSL), Nuraghe Crichidoris (NRC) and Contrada Misteci (CNM). In Figures 7 and 8 we show the behaviour of the total field intensity $(\mathrm{F})$, horizontal and vertical intensity ( $\mathrm{H}$ and $\mathrm{Z}$ ) and declination (D) at the two observatories from 1979 to 2010 (annual mean values) and those predicted by IGRF, ITGRF, INGRF and INGRF_reduced. An offset for the horizontal intensity of the planetary models as IGRF and derived ITGRF appears. This could 

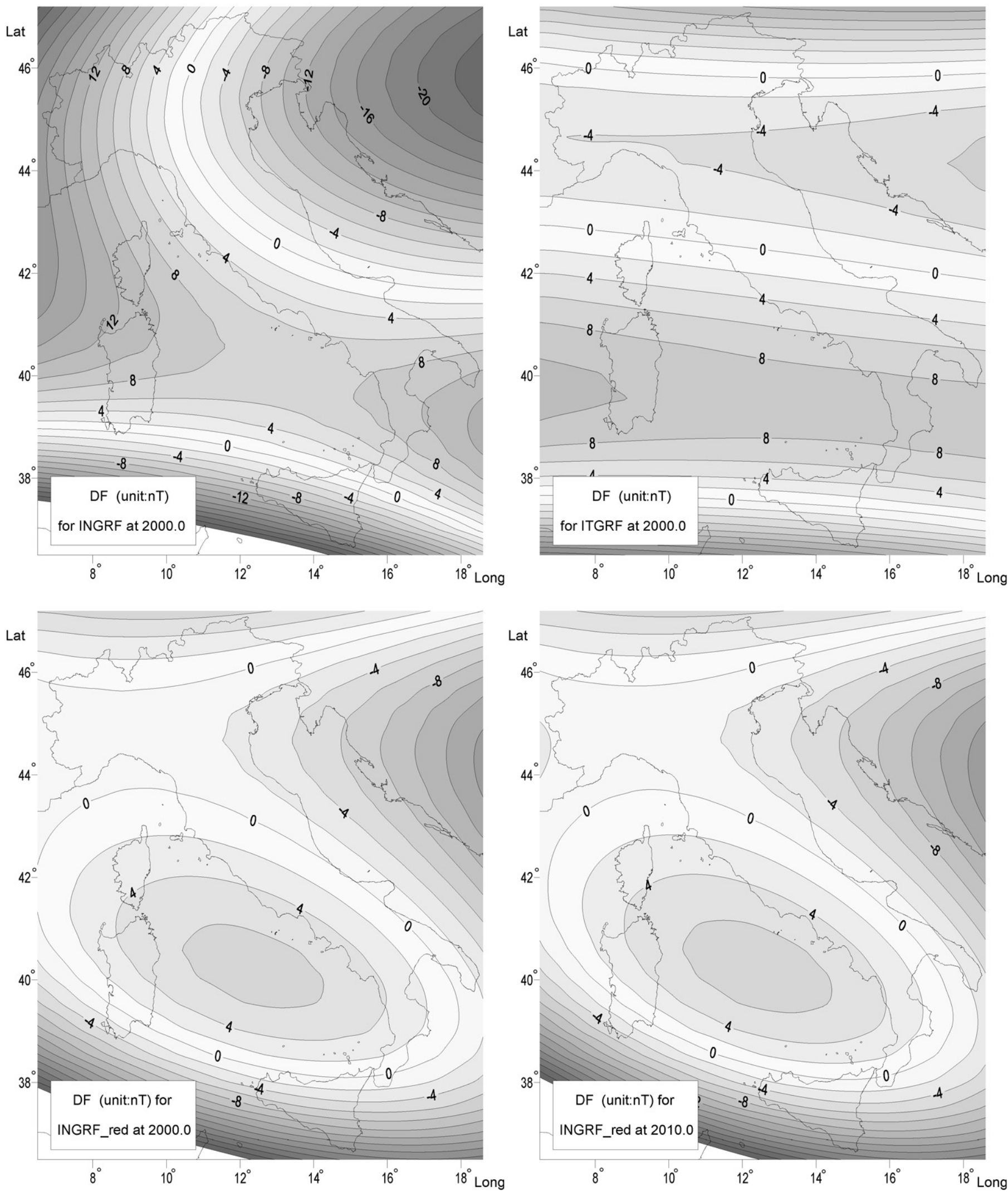

Figure 6. Geometrical condition $D F=F-\sqrt{H^{2}+Z^{2}}$ for the normal fields INGRF and ITGRF at epoch 2000.0 and for normal field INGRF_reduced, at epochs 2000.0 and 2010.0 .

easily be due to a bad elimination of the external field. For the observatory of Castello Tesino the INGRF data behaviour, in the period 1985-1990, is better fitted probably because in this case an intermediate model at 1987.5 was used, based on a specific reduced survey (see Table 1).
The comparison between CTS and CNM (Figure 9) shows we can estimate the behaviour of the various models in latitude, similarly to NRC (Figure 10) and MSL (Figure 11), in longitude. As for the observatories, for these stations the best estimation of horizontal intensity for the 

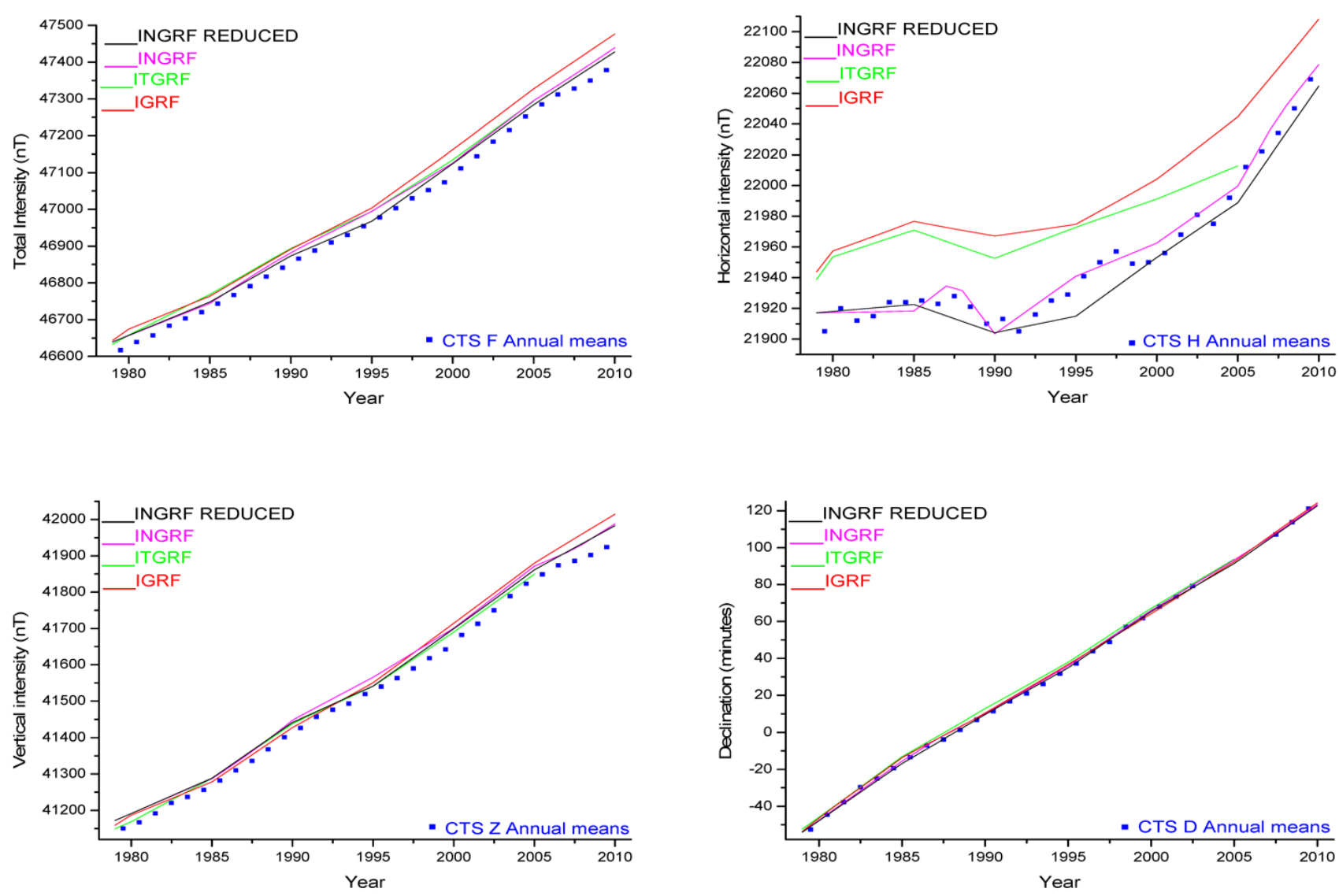

Figure 7. Annual mean values of F, H, Z, D computed at Castello Tesino observatory (squares) together with the values predicted by various models (coloured lines).
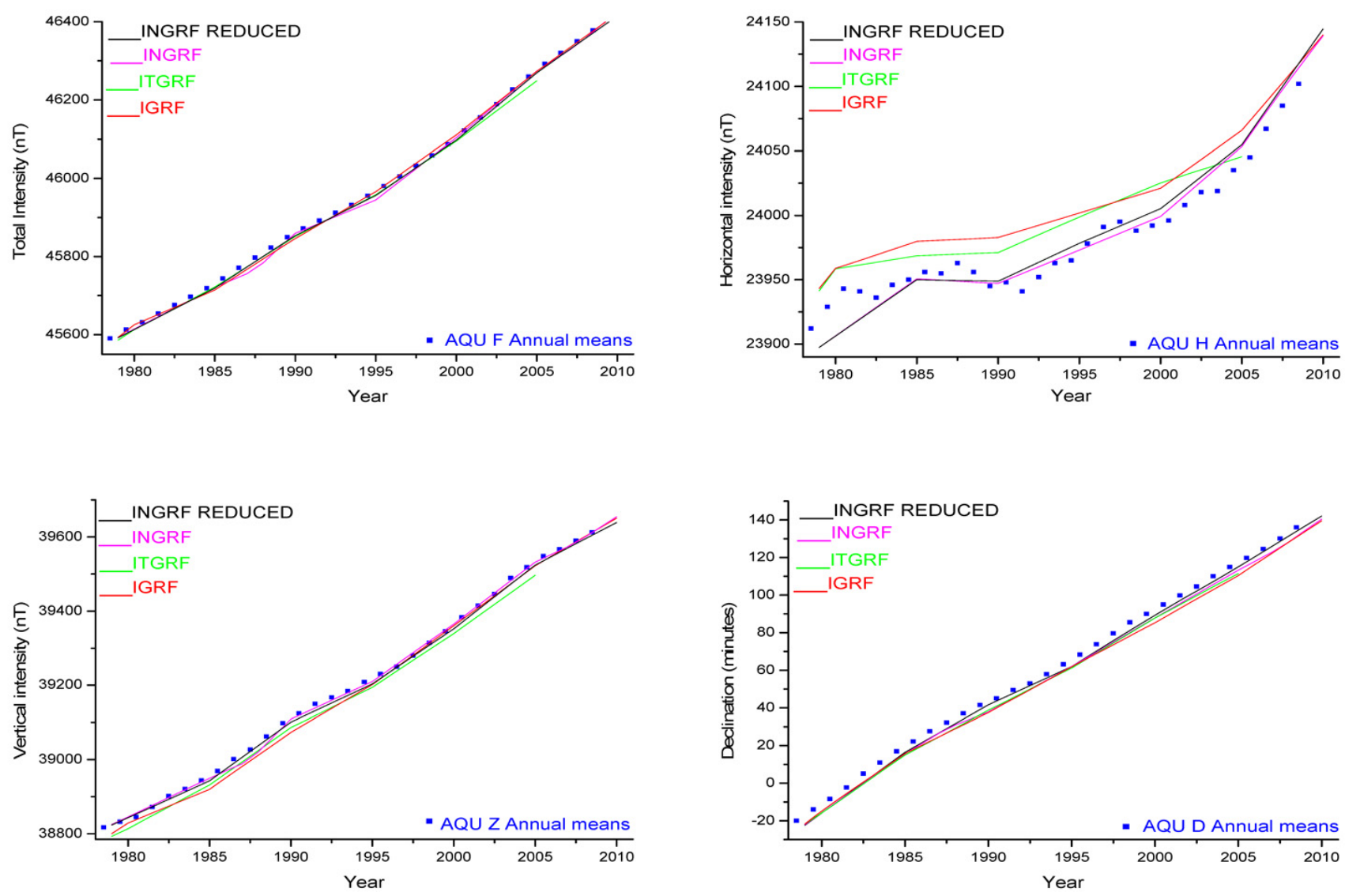

Figure 8. Annual mean values of F, H, Z, D computed at L'Aquila observatory (squares) together with the values predicted by various models (coloured lines). 

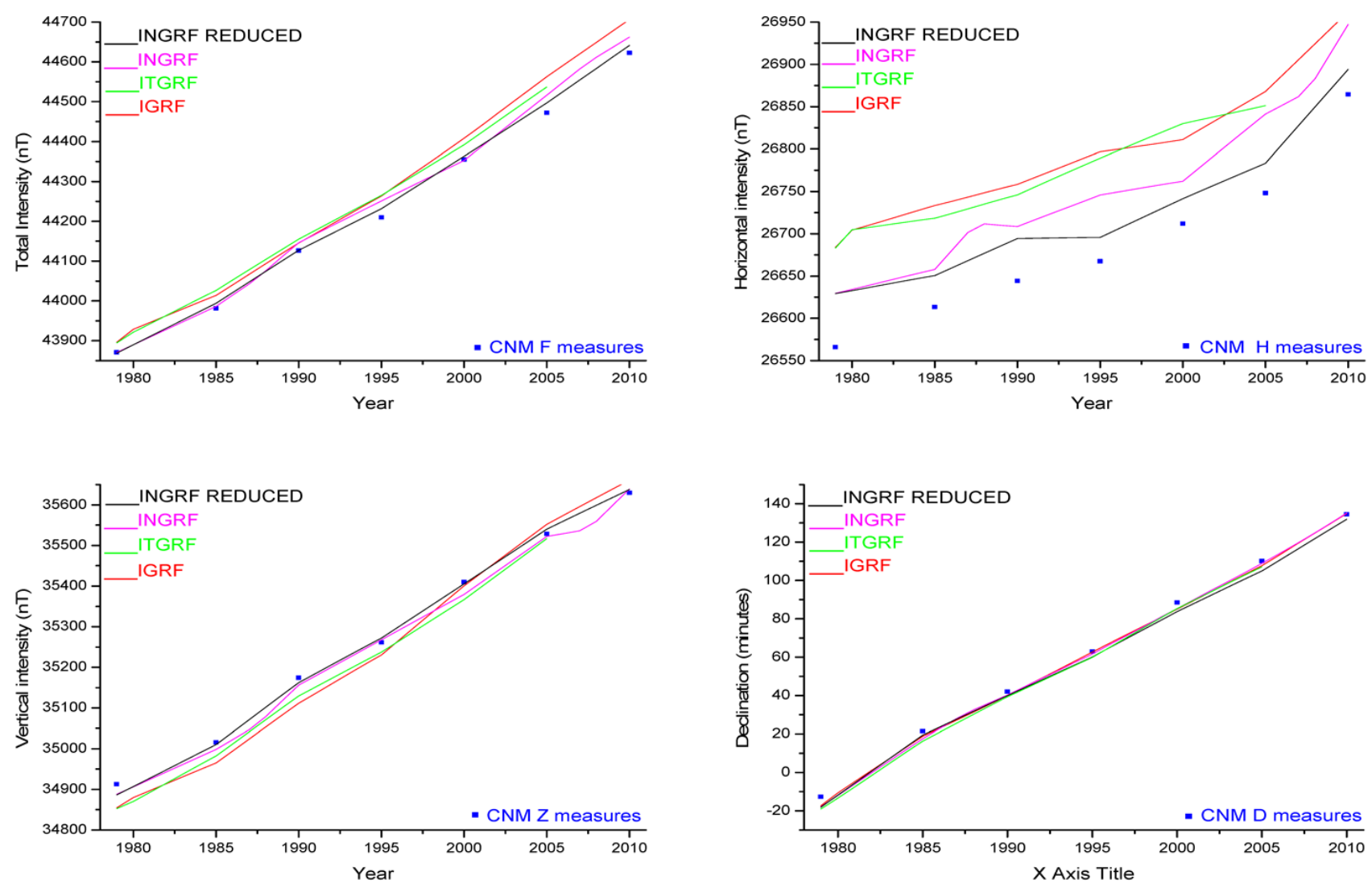

Figure 9. Measures of F, H, Z, D at CNM station (squares) together with the values predicted by various models (coloured lines).
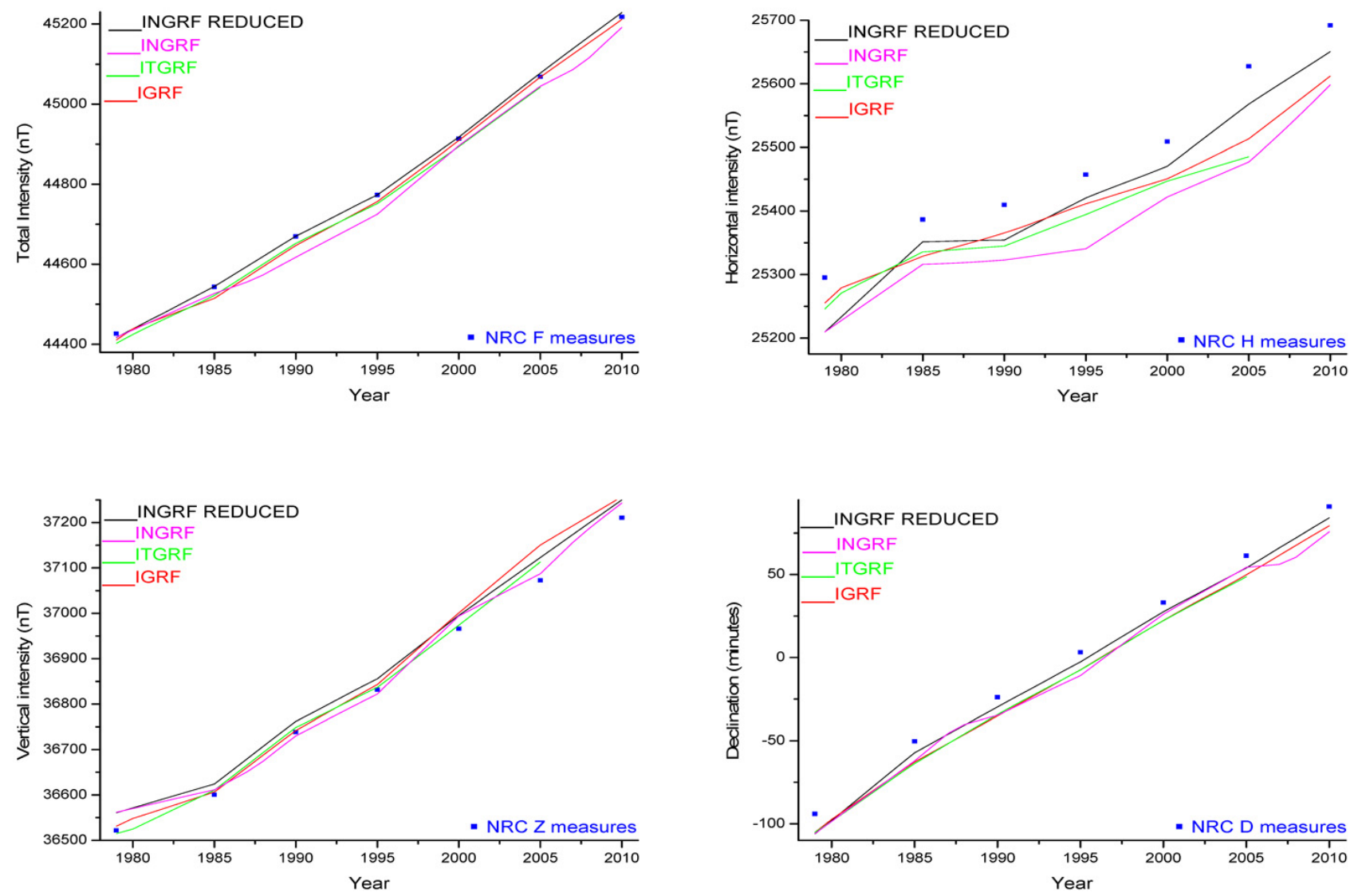

Figure 10. Measures of F, H, Z, D at NRC station (squares) together with the values predicted by various models (coloured lines). 

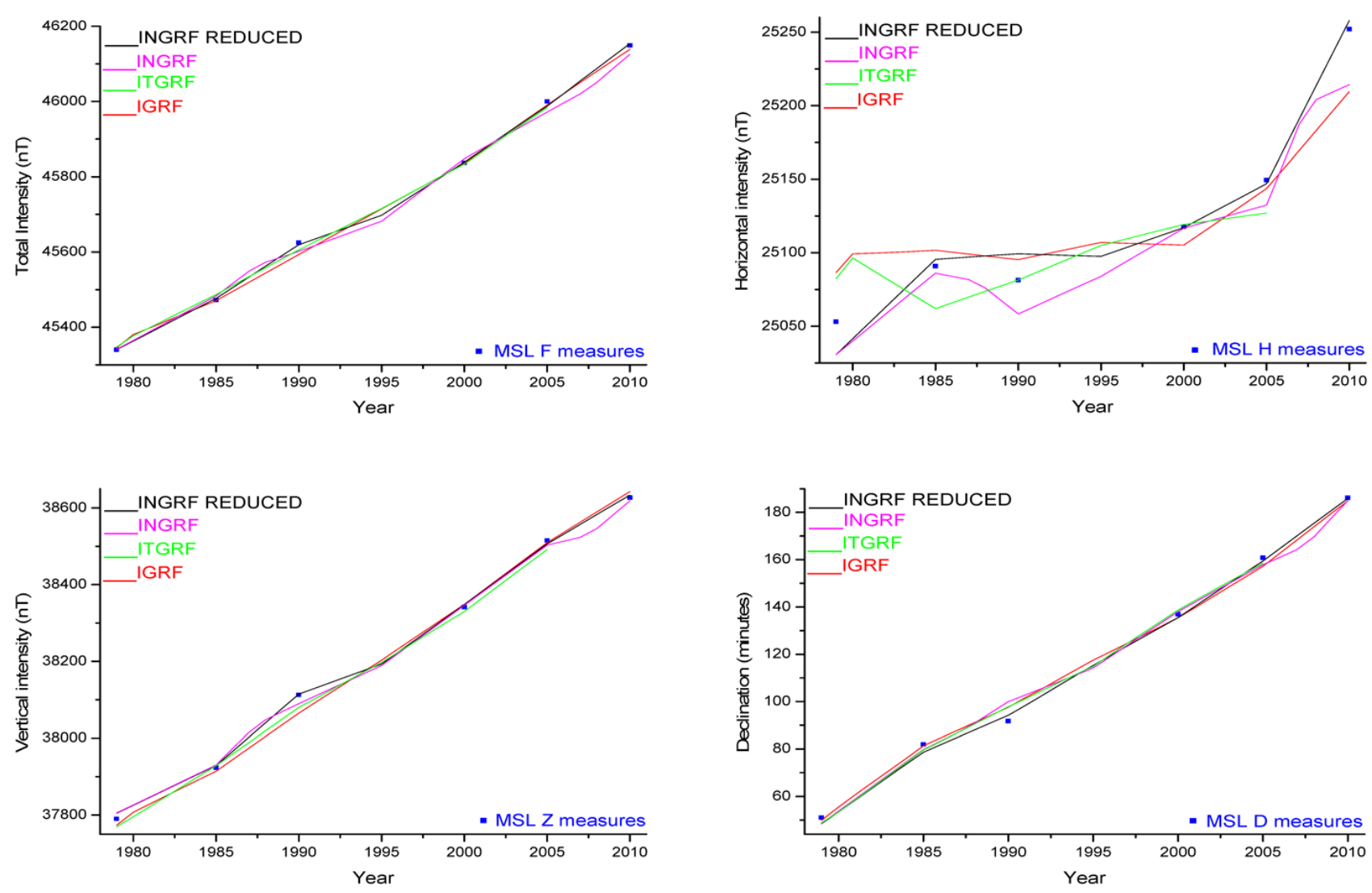

Figure 11. Measures of F, H, Z, D at MSL station (squares) together with the values predicted by various models (coloured lines).

INGRF_reduced is apparent. It's important to note that a bad choice of stations for a reduced network will involve possible errors of computation of normal fields because the weight of an anomalous station it's higher and it's visible in Figures 9-11 for INGRF model at the epochs 1987.5 and 1995 and 2007.5 generated with non balanced reduced networks.

The characteristics of magnetic first and second order networks in Italy and some surrounding areas, the magnetic measurements and reduction procedure, were described in this paper. Following the recommendations of MagNetE Committee, new repeat stations were measured and data finally reduced at 2010.0. The regional and/or normal field computation for the Italian region, an analytical expression of second order degree polynomial type, in latitude and longitude, was chosen for all elements, the coefficients of expression of normal fields at 2010.0 were computed and compared in order to make all possible standard modelling available to the scientific community.

\section{References}

Cafarella, L., A. De Santis and A. Meloni (1992a). Secular variation from historical geomagnetic field measurements, Phys. Earth Planet. Inter., 73, 206-221.

Cafarella, L., A. De Santis and A. Meloni (1992b). Il Catalogo geomagnetico storico italiano, Pubblicazioni dell'Istituto Nazionale di Geofisica vol. 7, 160 pp.

Campbell, W.H. (2003). Introduction to Geomagnetic Fields,
Cambridge University Press, 337 pp.

Chiappini, M., O. Battelli, S. Bushati, G. Dominici, B. Duka and A. Meloni (1997). The Albanian Geomagnetic Repeat Station Network at 1994.75, Journal of Geomagnetism and Geoelectricity, 49, 701-707.

Coticchia, A., A. De Santis, A. Di Ponzio, G. Dominici, A. Meloni, M. Pierozzi and M. Sperti (2001). La Rete Magnetica Italiana e la carta magnetica d'Italia al 2000.0/ Italian Magnetic Network and Geomagnetic Field Maps of Italy, Bollettino di Geodesia e Scienze Affini, 4, 261-291.

De Santis, A., L. Gaya-Piquè, G. Dominici, A. Meloni, J.M. Torta and R. Tozzi (2003). ITalian Geomagnetic Reference Field (ITGRF): update for 2000 and secular variation model up to 2005 by autoregressive forecasting, Annals of Geophysics, 46 (3), 491-500.

Dominici, G., A. Meloni, M. Miconi, M. Pierozzi and M. Sperti (2007). La Rete Magnetica Italiana e la carta magnetica d'Italia al 2005.0 / Italian Magnetic Network and Geomagnetic Field Maps of Italy at year 2005.0, Bollettino di Geodesia e Scienze Affini, 1,1-47.

IAGA (International Association of Geomagnetism and Aeronomy) Working Group V-MOD (2010). International Geomagnetic Reference Field: the eleventh generation, Geophysical Journal Intrenational, 183, 1216-1230.

Jankowski, J., and C. Suckdorff (1996). Guide for magnetic measurements and observatory practice, IAGA, Warsaw.

Korte, M., and M. Fredow (2001). Magnetic repeat station survey of Germany 1999/2000, Scientific Technical Re- 
port 01/04, Potsdam, Deutsches GeoForschungsZentrum GFZ, 23 pp.

Lanza, R., and A. Meloni (2006). The Earth's Magnetism: An Introduction for Geologists, Springer, $290 \mathrm{pp}$.

Mandea, M. (2004). Reseau magnétique de répétition de la France 2002, Bureau Central de Magnetisme terrestre, Paris, Bullettin n. 20.

Meloni, A., O. Battelli, G. Dominici, S. Arca and A. Marchetta (1988). Italian magnetic network at 1985.0, Bollettino di Geodesia e Scienze Affini, 4, 339-350.

Meloni A., O. Battelli, A. De Santis and G. Dominici (1994). The 1990.0 magnetic repeat station survey and normal reference fields for Italy, Annali di Geofisica, 37 (5), 949-967.

Merril, R.T., M.W. McElhinny and P.L. McFadden (1996). The magnetic field of the Earth: Paleomagnetism, the Core and the Deep Mantle, Academic Press, San Diego, California, $531 \mathrm{pp}$.

Molina, F., E. Armando, R. Balia, O. Battelli, E. Bozzo, G. Budetta, G. Caneva, M. Ciminale, N. De Florentiis, A. De Santis, G. Dominici, M. Donnaloia, A. Elena, V. Iliceto, R. Lanza, M. Loddo, A. Meloni, E. Pinna, G. Santarato, R. Zambrano (1985). Geomagnetic Survey of Italy. Repeat Stations Network and Magnetic Maps: a Short Report, Annales Geophysicae, 3 (3), 365-368.

Newitt, L.R., C.E. Barton and J. Bitterly (1996). Guide for magnetic repeat station surveys, IAGA Working Group.

Shepard, D. (1968). A two-dimensional interpolation function for irregularly-spaced data, In: Proceedings $23^{\text {rd }} \mathrm{Na}$ tional Conference ACM, ACM, 517-524.

Talamo, R. (1975). Le carte magnetiche d'Italia delle isodinamiche della $\mathrm{H}$ e delle isogone dell'Istituto Militare e loro aggiornamento al 1973.0, Bollettino di Geodesia e Scienze Affini, 34 (1).

\footnotetext{
${ }^{\star}$ Corresponding author: Guido Dominici, Istituto Nazionale di Geofisica e Vulcanologia, Roma, Italy; email: guido.dominici@ingv.it.

(C) 2012 by the Istituto Nazionale di Geofisica e Vulcanologia. All rights reserved.
} 